BUDGETING : Journal of Business, Management and Accounting

Volume 1, Nomor 2, Juni 2020

e-ISSN: $2715-2480$

p-ISSN: 2715-1913

DOI : https://doi.org/10.31539/budgeting.vli2.778

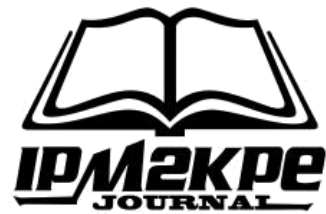

\title{
STRATEGI PENINGKATAN PBB P2 TERHADAP PENDAPATAN ASLI DAERAH DENGAN PERSPEKTIF WAJIB PAJAK
}

\author{
Moch Anas Kurniawan ${ }^{1}$, Dwi Cahyono ${ }^{2}$, Achmad Syahfrudin ${ }^{3}$ \\ Universitas Muahammadiyah Jember ${ }^{1,2,3}$ \\ anaskurnia1@ gmail.com ${ }^{1}$
}

\begin{abstract}
ABSTRAK
Tujuan Penelitian ini untuk menganalisa pengaruh sanksi perpajakan, sikap wajib pajak, kesadaran wajib pajak dan pengetahuan perpajakan dalam meningkatkan Pendapatan Asli Daerah (PAD) Kabupaten Jember. Penelitian ini merupakan penelitian kuantitatif dengan pendekatan deskriptif. Sampel sebanyak 100 responden diperoleh dengan teknik cluster sampling. Data diperoleh menggunakan kuesioner dan di analisis menggunakan dua metode analisis yaitu analisis deskriptif kuantitatif dan Analisis Trend. Hasil penelitian menunjukkan bahwa kendala yang dialami oleh pemerintah Kabupaten Jember adalah karena PBB P2 merupakan pajak baru sehingga pemda mengalami kesulitan dalam pengelolaannya, sarana dan prasarana yang kurang memadai serta membutuhkan biaya yang besar, serta sumber daya manusia yang tidak optimal dalam memberikan pelayanan. Pemerintah Kabupaten Jember melakukan tiga tahapan strategi yaitu tahap perencanaan strategi, pelaksanaan strategi, dan evaluasi strategi. Simpulan, Sanksi perpajakan berpengaruh secara signifikan dan positif terhadap peningkatan PAD, sikap wajib pajak, kesadaran wajib pajak, pengetahuan perpajakan tidak berpengaruh secara signifikan namun memiliki pengaruh positif terhadap peningkatan PAD Kabupaten Jember.
\end{abstract}

Kata Kunci : Strategi, PBB P2, Perspektif Wajib Pajak

\section{ABSTRACT}

The purpose of this study is to analyze the effect of taxation sanctions, taxpayer attitudes, taxpayer awareness and tax knowledge in increasing Jember Regency Regional Revenue (PAD). This research is a quantitative research with a descriptive approach. A sample of 100 respondents was obtained by cluster sampling technique. Data were obtained using a questionnaire and analyzed using two analytical methods, namely quantitative descriptive analysis and trend analysis. The results showed that the obstacle experienced by the Jember Regency government was because PBB P2 was a new tax so that the local government experienced difficulties in its management, inadequate facilities and infrastructure and large costs, and human resources that were not optimal in providing services. The Jember Regency Government carries out three stages of strategy, namely the strategic planning stage, strategy implementation and strategy evaluation. Conclusion, tax sanctions have a significant and positive effect on the increase in PAD, attitudes of taxpayers, awareness of taxpayers, knowledge of taxation has no significant effect but has a positive influence on the increase in PAD in Kabupaten Jember

Keywords: Strategy, PBB P2, Taxpayer Perspective 


\section{PENDAHULUAN}

Menurut Undang-Undang Nomor 28 Tahun 2009 menyatakan Pajak Bumi dan Bangunan Perdesaan dan Perkotaan ialah pajak atas bumi dan bangunan yang dimiliki, dikuasai dan dimanfaatkan oleh orang pribadi maupun badan, kecuali kawasan yang digunakan untuk kegiatan usaha perkebunan, perhutanan dan pertambangan. Pajak Bumi dan Bangunan Perdesaan dan Perkotaan (PBB-P2) yang awalnya merupakan pajak pusat kini menjadi pajak daerah. Selanjutnya pajak dikelola langsung oleh pemerintah daerah dan hasil dari pengelolaan pajak tersebut merupakan pendapatan bagi Pemerintah Asli Daerah (PAD).

Suatu daerah mempunyai hak untuk mengatur, mendapatkan dan memelihara aspek sumber Pendapatan Asli Daerah yang seluruhnya dikelola oleh pemerintah daerah itu sendiri tanpa ada lagi bagi hasil pajak kepada pemerintah pusat. Pendapatan Asli Daerah (PAD) adalah pendapatan daerah yang dipungut berdasarkan peraturan daerah sesuai peraturan perundang-undangan, seperti pajak daerah, retribusi daerah, perusahaan daerah dan lain-lain penerimaan yang sah (Suhadak dan Nugroho, 2007). Oleh karena itu, pemerintah daerah perlu meningkatkan penerimaan Pajak Bumi dan Bangunan Perdesaan dan Perkotaan (PBB-P2) sebagai sumber Pendapatan Asli Daerah (PAD). Namun hal ini tidak sesuai dengan semestinya pemungutan pajak bukanlah hal yang mudah dari tahun ke tahun selalu menjadi permasalahan hal ini masih disebabkan tidak percayanya masyarakat terhadap aparat perpajakan serta tingkat kepatuhan wajib pajak masih sangat rendah.

Salah satu upaya untuk meningkatkan Penerimaan Pajak Bumi dan Bangunan Perdesaan dan Perkotaan (PBB-P2) adalah dengan menerapkan sanksi pajak, pelayanan pajak dan kepatuhan pajak. Realisasi Pajak Bumi dan Bangunan Perdesaan dan Perkotaan (PBB-P2) Kabupaten Jember pada tahun 2015 sebesar 35.523.880.818 atau 71\% dari target APBD 50.000.000.000, tahun 2016 sebesar 33.754.396.739,24 atau 68\% dari target APBD sejumlah 49.900.000.000 dan tahun 2017 realisasi PAD sebesar 36.474.171.679 atau sebanyak 72\% dari target 50.503.000.000 (Kantor Dinas Pendapatan Daerah Kabupaten Jember)

Dari daftar realisasi penerimaan Pajak Bumi dan Bangunan Perdesaan dan Perkotaan Kabupaten Jember tahun 2015-2017 di atas menunjukkan Kabupaten Jember mengalami ketidak tercapaian target karena realisasi penerimaan kurang dari target yang 
ditetapkan. Hal ini menunjukkan bahwa potensi PBB-P2 belum terealisasi secara sempurna hal ini nantinya berdampak terhadap penerimaan Pendapatan Asli Daerah. Berdasarkan beberapa alasan yang telah dikemukakan di atas maka peneliti ingin melakukan penelitian mengenai Pengaruh Penerimaan Pajak Bumi dan Bangunan Perdesaan dan Perkotaan terhadap Pendapatan Asli Daerah Tahun 2015-2017 di Kantor Badan Pendapatan Daerah Kabupaten Jember (Studi kasus pada wajib pajak Kecamatan Sumbersari Jember).

Berdasarkan latar belakang diatas, rumusan masalah yang penulis rumuskan yaitu belum terpenuhinya target APBD terhadap penerimaan Pajak Bumi dan Bangunan Perdesaan dan Perkotaan pada Kantor Dinas Pendapatan Daerah Kabupaten Jember. Adapun tujuan penelitian ini adalah untuk mengetahui pengaruh sanksi perpajakan, pengaruh sikap wajib pajak terhadap Pendapatan Asli Daerah, kesadaran wajib pajak, pengetahuan perpajakan terhadap Pendapatan Asli Daerah di Kabupaten Jember

\section{KAJIAN TEORI}

Pajak adalah kontribusi wajib kepada negara yang terutang oleh orang pribadi atau badan yang bersifat memaksa berdasarkan Undang-Undang, dengan tidak mendapatkan imbalan secara langsung yang digunakan untuk keperluan negara bagi sebesar-besarnya kemakmuran rakyat (UU No.28 Tahun 2007 tentang KUP). Di Indonesia, Pajak merupakan sumber penerimaan negara yang sangat besar kontribusinya dalam membiayai kebutuhan belanja negara dan pembangunan nasional. Dimana hal tersebut tercermin dalam Anggaran Pendapatan dan Belanja Negara (APBN).

Pengertian sanksi perpajakan menurut Mardiasmo (2005) yaitu sanksi perpajakan merupakan jaminan bahwa ketentuan peraturan perundang-undangan perpajakan (norma perpajakan) akan dituruti/di patuhi bisa dengan kata lain sanksi perpajakan merupakan alat pencegah (prefentif), agar wajib pajak tidak melanggar norma perpajakan

Sikap adalah pernyataan evaluatif baik yang menguntungkan atau tidak tentang objek, orang atau peristiwa (Robbinson, 2001). Apabila wajib pajak merasa bahwa keadilan pajak telah diterapkan kepada semua wajib pajak dengan tidak membedakan perlakuan antara wajib pajak badan dengan perorangan, wajib pajak besar dengan wajib pajak kecil dalam artian bahwa semua wajib pajak diperlakukan secara adil maka setiap 
wajib pajak cenderung untuk menjalankan kewajiban pajaknya dengan baik atau dengan kata lain menimbulkan kepatuhan dalam diri wajib pajak (Sutrisno, 2009). Berdasarkan definisi dapat disimpulkan bahwa sikap wajib pajak adalah pernyataan, pertimbangan atau perspektif individu dari wajib pajak yang menjadi dasar interaksi dengan orang lain atau peristiwa, baik itu menguntungkan atau tidak menguntungkan mengenai suatu objek.

Kesadaran perpajakan adalah suatu sikap sadar terhadap fungsi pajak, berupa konstelasi komponen kognitif, afektif dan konatif, yang berinteraksi dalam memahami, merasakan dan berperilaku terhadap makna dan fungsi pajak. Kesadaran perpajakan berkonsekuensi logis untuk wajib pajak, yaitu kerelaan wajib pajak memberikan kontribusi dana untuk pelaksanaan fungsi perpajakan, dengan cara membayar kewajiban pajaknya secara tepat waktu dan tepat jumlah (Harmawati \& Yadnyana, 2016).

Pengetahuan adalah hasil tahu manusia terhadap sesuatu, atau segala perbuatan manusia untuk memahami suatu objek tertentu yang dapat berwujud barang-barang baik lewat indera maupun lewat akal, dapat pula objek yang dipahami oleh manusia berbentuk ideal, atau yang bersangkutan dengan masalah kejiwaan. Pajak adalah iuran rakyat kepada kas negara berdasarkan undang-undang (yang dapat dipaksakan) dengan tidak mendapat jasa timbal yang langsung dapat ditunjukan dan yang digunakan untuk membayar pengeluaran umum (Mardiasmo, 2009).

Berdasarkan Undang-undang No. 28 Tahun 2009 tentang pajak daerah dan retribusi daerah, PBB-P2 adalah pajak atas bumi dan/atau bangunan yang dimiliki, dikuasai, dan/atau dimanfaatkan oleh orang pribadi atau badan, kecuali kawasan yang digunakan untuk kegiatan usaha perkebunan, perhutanan, dan pertambangan. Bumi adalah permukaan bumi yang meliputi tanah dan perairan pedalaman serta laut wilayah kabupaten/kota. Bangunan adalah konstruksi teknik yang ditanam atau dilekatkan secara tetap pada tanah dan atau perairan pedalaman dan/atau laut.

Menurut Halim (2007), Pendapatan Asli Daerah merupakan semua penerimaan yang berasal dari sumber ekonomi asli daerah. Kelompok PAD dipisahkan menjadi empat jenis pendapatan, yaitu; Pajak Daerah, Retribusi Daerah, Hasil Pengelolaan kekayaan milik daerah yang dipisahkan dan lain-lain PAD yang sah. 


\section{METODE PENELITIAN}

Jenis data dalam penelitian ini adalah kuantitatif dengan pendekatan deskriptif, kuantitatif ialah pendekatan yang di dalam usulan penelitian, proses, hipotesis, turun ke lapangan, analisis data dan kesimpulan data sampai dengan penulisannya mempergunakan aspek pengukuran, perhitungan, rumus dan kepastian data numeric (Sugiyono, 2008). Penelitian ini menggunakan pendekatan deskriptif dengan tujuan untuk mendeskripsikan objek penelitian ataupun hasil penelitian (Arikunto, 2010). Populasi sampel dalam penelitian ini adalah seluruh wajib pajak di Kabupaten Jember yang terdaftar di Kantor Badan Pendapatan Daerah Kabupaten Jember berjumlah 1.024.530 wajib pajak. Dalam pengambilan sampel dalam penelitian ini adalah metode Cluster Sampling, Teknik pengumpulan data yang digunakan oleh peneliti dalam penelitian ini adalah dengan menggunakan metode survey dengan teknik penyebaran kuesioner, dimana sejumlah pertanyaan tertulis disampaikan pada responden dan menggunakan teknik wawancara untuk memperoleh gambaran tentang PBB-P2 di Kabupaten Jember. Dalam penelitian ini dilakukan dua metode analisis yang pertama yaitu analisis deskriptif kuantitatif dan Analisis Trend.

Metode Trend Least Square digunakan untuk forecast dimana teknik statistika dan matematis dipakai sebagai alat primer dalam penyusunan peramalan, sedangakan pendapat dipakai sebagai pelengkap. Metode Kuadrat Terkecil (Least Square Method) adalah metode untuk menghitung nilai trend pada tahun berjalan dan untuk mencari forecast pada periode yang akan datang. Untuk menghitung nilai trend dan forecast terlebih dahulu harus menaksir nilai a dan $b$ pada persamaan berikut ini $Y=a+b X$. Nilai $\mathrm{X}$ dihitung dengan mengacu pada panduan, jika :

Data Gasal maka X:....., $-3,-2,-1,0,1,2,3, \ldots .$.

Data Genap maka X: ....., $-3,-1,1,3, \ldots .$.

Persamaan untuk menaksir nilai a dan $\mathrm{b}$ adalah:

$$
\mathbf{a}=\sum \mathbf{y} / \mathbf{n} \quad \mathbf{b}=\sum \mathbf{y} / \sum \mathbf{x} \mathbf{2}
$$

Keterangan :

$\mathrm{Y}=$ Variabel yang akan diramalkan

$\mathrm{a}=$ Konstanta

$\mathrm{b}=$ Koefisien Korelasi

$\mathrm{x}=$ Unit waktu/periode yang dapat dinyatakan dalam tahun 
Strategi Peningkatan PBB P2 Kabupaten Jember: Perencanaan strategi, pelaksanaan strategi dan evalusai strategi.

Uji Asumsi Klasik dengan melakukan Uji Normalitas, Uji Multikolinearitas dan Uji Heteroskedastisitas. Uji penelitian ini digunakan model analisis regresi berganda (multiple regression analysis). Model regresi berganda bertujuan untuk memprediksi besar variabel dependen dengan menggunakan data variabel independen yang sudah diketahui besarnya (Santoso, 2004). Untuk menguji hipotesis alat yang digunakan adalah regresi berganda. Dalam penggunaan alat uji regresi berganda terdapat beberapa analisis yang digunakan, yaitu : Uji Statistik t dan Uji Determinan $\left(\mathrm{R}^{2}\right)$.

\section{HASIL PENELITAN}

\section{Gambaran Umum Objek Penelitian}

Penelitian ini menggunakan data kuantitatif yang diperoleh dari penyebaran kuesioner kepada wajib pajak PBB P2 yang bertempat tinggal di wilayah kabupaten jember Kecamatan Sumbersari. Pengiriman kuesioner dilakukan dari awal bulan Juli 2019 dan proses pengembaliannya dilakukan sampai dengan pertengahan bulan Juli 2019. Kuesioner disebarkan kepada 100 responden. Dari 100 kuesioner yang di sebarkan semua kembali dengan lengkap dan memenuhi syarat untuk diolah.

Tabel 1.

Hasil Uji Deskriptif Kuantitatif

\begin{tabular}{cccccc}
\hline & $\mathbf{N}$ & Minimum & Maksimum & Mean & SD \\
\hline Total X1 & 100 & 9 & 24 & 17,79 & 3,118 \\
Total X2 & 100 & 8 & 24 & 18,90 & 2,866 \\
Total X3 & 100 & 9 & 24 & 19,18 & 3,264 \\
Total X4 & 100 & 10 & 28 & 21,99 & 2,323 \\
Total Y & 100 & 9 & 19 & 15,09 & \\
Valid & 100 & & & & \\
\hline
\end{tabular}

Tabel 2.

Uji Validitas untuk Sanksi Perpajakan

\begin{tabular}{cccc}
\hline Pernyataan & Pearson Correlation & Sig (2-tailed) & Keterangan \\
\hline X1.1 & $0,515^{* *}$ & 0,000 & Valid \\
X1.2 & $0,647^{* *}$ & 0,000 & Valid \\
X1.3 & $0,625^{* *}$ & 0,000 & Valid \\
X1.4 & $0,674^{* *}$ & 0,000 & Valid \\
X1.5 & $0,639^{* *}$ & 0,000 & Valid \\
XI.6 & $0,703^{* *}$ & 0,000 & Valid \\
\hline
\end{tabular}

Berdasarkan tabel 2 diatas dapat dilihat semua pernyataan dapat dikatakan valid karena setiap pernyataan memiliki nilai signifikan dibawah 0,05 
Tabel 3.

Uji Validitas untuk Sikap Wajib Pajak

\begin{tabular}{cccc}
\hline Pernyataan & Pearson Correlation & Sig (2-tailed) & Keterangan \\
\hline X2.1 & $0,624^{* *}$ & 0,000 & Valid \\
X2.2 & $0,716^{* *}$ & 0,000 & Valid \\
X2.3 & $0,570^{* *}$ & 0,000 & Valid \\
X2.4 & $0,721^{* *}$ & 0,000 & Valid \\
X2.5 & $0,665^{* *}$ & 0,000 & Valid \\
X2.6 & $0,716^{* *}$ & 0,000 & Valid \\
\hline
\end{tabular}

Berdasarkan tabel 3 diatas dapat dilihat semua pernyataan dapat dikatakan valid karena setiap pernyataan memiliki nilai signifikan dibawah 0,05

Tabel 4.

Uji Validitas untuk kesadaran wajib pajak

\begin{tabular}{cccc}
\hline Pernyataan & Pearson Correlation & Sig (2-tailed) & Keterangan \\
\hline X3.1 & $0,754^{* *}$ & 0,000 & Valid \\
X3.2 & $0,740^{* *}$ & 0,000 & Valid \\
X3.3 & $0,763^{* *}$ & 0,000 & Valid \\
X3.4 & $0,695^{* *}$ & 0,000 & Valid \\
X3.5 & $0,744^{* *}$ & 0,000 & Valid \\
X3.6 & $0,622^{* *}$ & 0,000 & Valid \\
\hline
\end{tabular}

Berdasarkan tabel 4 diatas dapat dilihat semua pernyataan dapat dikatakan valid karena setiap pernyataan memiliki nilai signifikan dibawah 0,05

Tabel 5.

Uji Validitas untuk Pengetahuan Perpajakan

\begin{tabular}{cccc}
\hline Pernyataan & Pearson Correlation & Sig (2-tailed) & Keterangan \\
\hline X4.1 & $0,723^{* *}$ & 0,000 & Valid \\
X4.2 & $0,669^{* *}$ & 0,000 & Valid \\
X4.3 & $0,670^{* *}$ & 0,000 & Valid \\
X4.4 & $0,667^{* *}$ & 0,000 & Valid \\
X4.5 & $0,759^{* *}$ & 0,000 & Valid \\
X4.6 & $0,677^{*}$ & 0,000 & Valid \\
X4.7 & $0,759^{* *}$ & 0,000 & Valid \\
\hline
\end{tabular}

Berdasarkan tabel 5 diatas dapat dilihat semua pernyataan dapat dikatakan valid karena setiap pernyataan memiliki nilai signifikan dibawah 0,05 . 
Tabel 6.

Uji Validitas untuk Pendapatan Asli Daerah

\begin{tabular}{cccc}
\hline Pernyataan & Pearson Correlation & Sig (2-tailed) & Keterangan \\
\hline Y.1 & $0,505^{* *}$ & 0,000 & Valid \\
Y.2 & $0,487^{* *}$ & 0,000 & Valid \\
Y.3 & $0,578^{* *}$ & 0,000 & Valid \\
Y.4 & $0,571^{*}$ & 0,000 & Valid \\
Y.5 & $0,581^{* *}$ & 0,000 & Valid \\
\hline
\end{tabular}

Berdasarkan tabel 6 diatas dapat dilihat semua pernyataan dapat dikatakan valid karena setiap pernyataan memiliki nilai signifikan dibawah 0,05 .

Uji reabilitas dilakukan untuk melihat apakah instrument yang digunakan reliable sebagai alat pengumpul data. dapat dilihat pada tabel 7 dibawah bahwa variabel Sanksi Perpajakan dapat dikatakan reliabel karena nilai alpha di atas 0,60 yaitu sebesar 0,753. Variabel Sikap Wajib Pajak juga dapat dikatakan reliabel karena nilai alpha diatas 0,60 yaitu sebesar 0,764. Variabel Kesadaran Wajib Pajak juga memiliki nilai diatas 0,60 dengan nilai sebesar 0,781. Variabel independen yang terakhir yaitu Pengetahuan Perpajakan juga dapat dikatakan reliabel karena nilai alpha di atas 0,60 yaitu sebesar 0,774. Sedangkan untuk variabel dependennya yaitu Pendapatan Asli Daerah dapat dikatakan reliabel karena nilai alpha di atas 0,60 yaitu sebesar 0,697.

Tabel 7.

Uji Reliabilitas

\begin{tabular}{lcl}
\hline \multicolumn{1}{c}{ Instrumen } & Cronbach's Alpha & Keterangan \\
\hline Sanksi Perpajakan & 0,753 & Reliabel \\
\hline Sikap Wajib Pajak & 0,764 & Reliabel \\
\hline Kesadaran Wajib Pajak & 0,781 & Reliabel \\
\hline Pengetahuan Perpajakan & 0,774 & Reliabel \\
\hline Pendapatan Asli Daerah & 0,697 & Reliabel \\
\hline Sumber: Data Primer Diolah & &
\end{tabular}

Hasil Analisis Trend Pajak Bumi dan Bangunan Perdesaan dan Perkotaan di Kabupaten Jember Kecamatan Sumbersari. Berikut ini adalah tren penerimaan Pajak Bumi dan Bangunan Perdesaan dan Perkotaan Tahun 2015-2017 di Kabupaten Jember. 


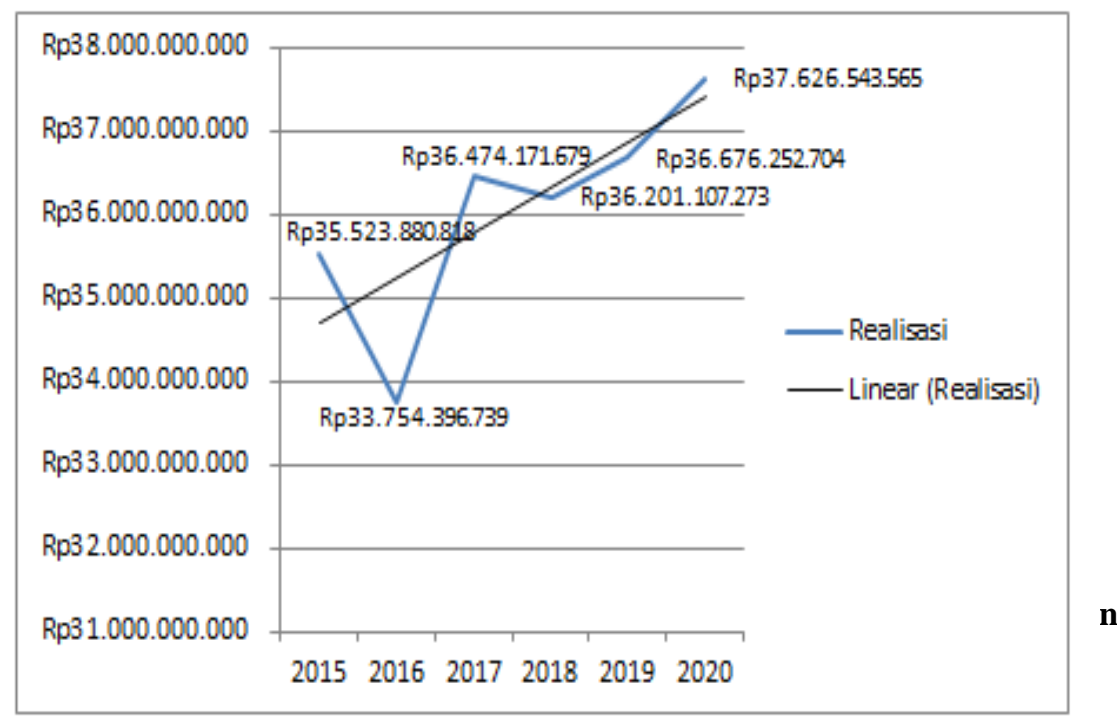

Sumber : Data Primer Diolah

Berdasarkan gambar Analisis Trend pada Penerimaan Pajak Bumi dan Bangunan Perdesaan dan Perkotaan Kabupaten Jember Kecamatan Sumbersari menghasilkan trend positif dimana garis trend cenderung mengalami kenaikan setiap tahun.

Hasil Uji Asumsi Klasik

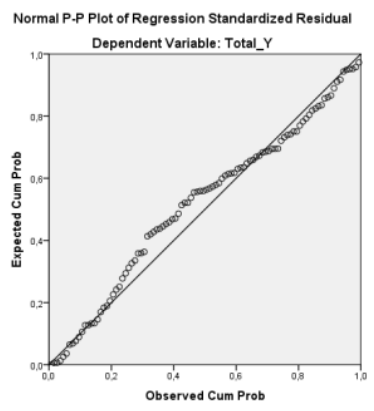

Gambar 2

Hasil Uji Normalitas

Gambar diatas menunjukkan data (titik) menyebar di sekitar garis diagonal dan mengikuti arah garis diagonal sehingga model regresi memenuhi asumsi normalitas.

Tabel 8.

Uji Multikolinearitas

\begin{tabular}{lcl}
\hline \multicolumn{1}{c}{ Variabel } & Tolerance & VIF \\
\hline Sanksi Perpajakan & 0,602 & 1,661 \\
\hline Sikap Wajib Pajak & 0.667 & 1,500 \\
\hline Kesadaran Wajib Pajak & 0,566 & 1,767 \\
\hline Pengetahuan Perpajakan & 0,580 & 1,723
\end{tabular}

Sumber : Data Primer Diolah 
Berdasarkan tabel 8 hasil uji multikolinearitas dapat dilihat melalui Variance Inflation Factor (VIF) masing-masing variabel independen memiliki VIF tidak lebih dari 10 dan nilai tolerance $>0,1$, maka dapat dinyatakan model regresi linier berganda terbebas dari asumsi multikolinieritas.

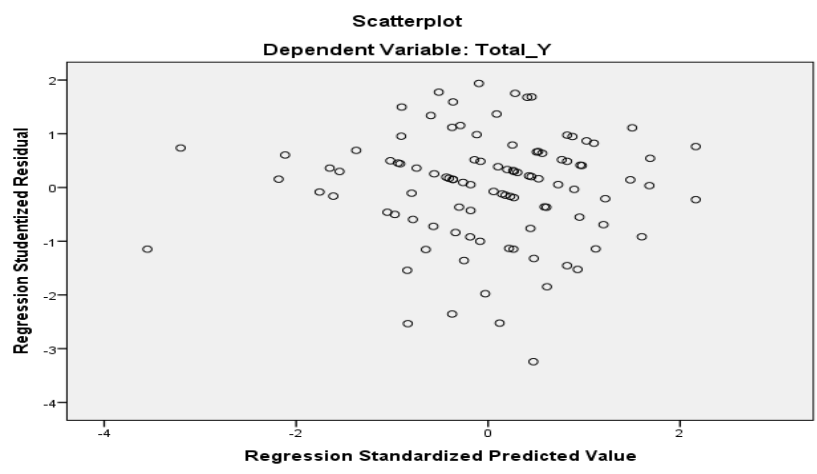

Gambar 3.

Uji Heterokedastisitas

Berdasarkan gambar 4.4 menunjukkan tidak terjadi heterokedastisitas karena titiktitik menyebar diatas dan dibawah nilai angka nol (0) pada sumbu $\mathrm{Y}$ dan tidak membentuk pola.Hasil Analisis Regresi Berganda

Tabel 9.

\section{Uji Signifikansi Parsial (Uji t)}

\begin{tabular}{|c|c|c|c|c|c|c|}
\hline \multicolumn{7}{|c|}{ Coefficients $^{\mathrm{s}}$} \\
\hline \multicolumn{2}{|r|}{ Model } & \multicolumn{2}{|c|}{ Unstandardized Coefficients } & \multirow{2}{*}{$\begin{array}{c}\begin{array}{c}\text { Standarized } \\
\text { Coefficients }\end{array} \\
\text { Beta }\end{array}$} & \multirow[t]{2}{*}{$\mathbf{t}$} & \multirow[t]{2}{*}{ Sig. } \\
\hline 1 & & B & Std Error & & & \\
\hline & (Constant) & 7,190 & 1,685 & & 4,267 & 0,000 \\
\hline & Total_X1 & ,201 & ,087 & 270 & 2,311 & 0,023 \\
\hline & Total_X2 &, 046 & ,090 &, 056 &, 509 & ,612 \\
\hline & Total_X3 & , 140 & ,086 & ,197 & 1,639 & , 105 \\
\hline & Total_X4 & ,036 & 079 &, 053 & ,448 & ,666 \\
\hline
\end{tabular}

DependentVariable: Total Y

Berdasarkan uji t statistik pada tabel 9 diatas menunjukkan bahwa :

Variabel Sanksi Perpajakan

Variabel Sanksi Perpajakan memiliki nilai signifikan sebesar 0,023 nilai ini lebih kecil dari 0,05. Maka dapat disimpulkan bahwa Sanksi Perpajakan $\left(\mathrm{X}_{1}\right)$ secara signifikan berpengaruh terhadap Pendapatan Asli Daerah dalam membayar PBB P2 di Kabupaten Jember.

Variabel Sikap Wajib Pajak 
Variabel Sikap Wajib Pajak memiliki nilai signifikan sebesar 0,612 nilai ini lebih besar dari 0,05. Maka dapat disimpulkan bahwa Sikap Wajib Pajak $\left(\mathrm{X}_{2}\right)$ tidak berpengaruh terhadap Pendapatan Asli Daerah dalam membayar PBB P2 di Kabupaten Jember.

Variabel Kesadaran Wajib Pajak

Variabel Kesadaran Wajib Pajak memiliki nilai signifikan sebesar 0,105 nilai ini lebih besar dari 0,05. Maka dapat disimpulkan bahwa Kesadaran Wajib Pajak $\left(\mathrm{X}_{3}\right)$ tidak berpengaruh terhadap Pendapatan Asli Daerah dalam membayar PBB P2 di Kabupaten Jember.

Variabel Pengetahuan Perpajakan

Variabel Pengetahuan Perpajakan memiliki nilai signifikan sebesar 0,655 nilai ini lebih besar dari 0,05. Maka dapat disimpulkan bahwa Pengetahuan Perpajakan $\left(\mathrm{X}_{4}\right)$ tidak berpengaruh terhadap Pendapatan Asli Daerah dalam membayar PBB P2 di Kabupaten Jember.

Tabel 10.

Uji Determinan $\left(\mathbf{R}^{2}\right)$

\begin{tabular}{|c|c|c|c|c|c|}
\hline Model & $\mathbf{R}$ & R Square & $\begin{array}{c}\text { Ajusted R } \\
\text { Square }\end{array}$ & $\begin{array}{l}\text { Std. error of } \\
\text { the Estimate }\end{array}$ & $\begin{array}{l}\text { Durbin- } \\
\text { Watson }\end{array}$ \\
\hline 1 &, 471 &, 222 & , 189 & 2,092 & 1,865 \\
\hline $\begin{array}{ll}\text { a. } & \mathrm{P} \\
\text { b. } & \mathrm{D}\end{array}$ & \multicolumn{5}{|c|}{$\begin{array}{l}\text { Predictors:(Constant), Total_X4, Total_X2, total_X1, Total_X3 } \\
\text { Dependent Variabel: Total_Y }\end{array}$} \\
\hline
\end{tabular}

Berdasarkan tabel 10 diatas besarnya adjusted $\mathrm{R}^{2}$ adalah 0,189 hal ini menunjukkan 18,9 \% variabel dependen Pendapatan Asli Daerah dalam membayar PBB P2 dapat dijelaskan oleh variabel independen yang meliputi Sanksi Perpajakan, Sikap Wajib Pajak, Kesadaran Wajib Pajak dan Pengetahuan Perpajakan. Sedangkan sisanya sebesar $81,1 \%$ dipengaruhi oleh variabel lain.

\section{PEMBAHASAN}

\section{Perencanaan Strategi}

Perencanaan strategi yang pertama dalam meningkatkan PBB P2 yaitu dengan menentukan sistem pembayaran yang akan digunakan dalam memungut pajak tersebut. Pemerintah Kabupaten Jember menerapkan official assessment. Pembayaran melalui bank atau yang disebut dengan payment online. Bank yang ditunjuk dalam pemungutan 
PBB P2 adalah Bank Jatim. Alasannya karena Bank Jatim merupakan bank yang telah ditunjuk oleh pemerintah Kabupaten Jember. Perencanaan yang kedua yaitu dengan menyiapkan sumber daya manusia yang memadai dan bisa memanfaatkan teknologi yang digunakan dalam pemungutan PBB P2 sehingga dapat memberikan pelayanan yang optimal kepada wajib pajak yang akan melakukan PBB P2.

\section{Pelaksanaan Strategi}

Dalam melaksanakan strategi sebelumnya dilakukan sosialisasi terlebih dahulu kepada wajib pajak dalam pemungutan PBB P2. Sosialisasi ini bertujuan untuk menyadarkan bahwa pentingnya wajib pajak dalam berpartisipasi membayar pajak yang menjadikan tanggung jawabnya bukan semata-mata iuran yang tanpa imbal jasa, namun merupakan investasi yang diberikan kepada negara khususnya pemerintah daerah agar dapat menyediakan fasilitas publik yang lebih baik. Selanjutnya yaitu proses pelaksanaan pemungutan PBB P2 dilapangan. Dalam hal ini wajib pajak dapat melakukan pembayaran PBB P2 kepada Bank Jatim. Prosedurnya yaitu dalam melakukan PBB P2 yang diperlukan adalah adanya Surat Pemberitahuan Pajak Tahunan Pajak Bumi Dan Bangunan Perdesaan Dan Perkotaan. Surat inilah yang akan mencantumkan seberapa besar pajak yang harus dibayarkan.

\section{Evaluasi Strategi}

Evaluasi strategi merupakan tahapan terakhir didalam proses peningkatan PBB P2. Menurut Juwono (2011), evaluasi mencangkup 3 hal yaitu meninjau faktor internal dan eksternal yang menjadi dasar bagi strategi yang berlangsung, mengukur kinerja yang telah dilakukan dan mengambil berbagai tindakan yang harus dilakukan guna memperbaiki hal-hal yang dapat menyebabkan penerimaan PBB P2 tidak maksimal. Dalam penerimaan PBB P2 di Kabupaten Jember evaluasi telah dilakukan mengingat program pemerintah ini sudah berjalan. Dari kegiatan evaluasi yang telah dilakukan, ditemukan beberapa hal yang menjadi penghambat dalam penyerapan penerimaan PBB P2 di Kabupaten Jember salah satunya adalah tidak akuratnya data wajib pajak PBB P2. Ketidak akuratan ini dikarenakan tidak maksimalnya pendataan. Untuk menindak lanjuti ketidak akuratan data DISPENDA turun langsung kelapangan guna memperoleh data 
secara rill mengenai data wajib pajak PBB P2 yang digunakan sebagai dasar pengenaan PBB P2 kepada wajib pajak.

\section{SIMPULAN}

Berdasarkan hasil penelitian yang telah dilakukan dapat diambil kesimpulan sebagai berikut; 1) Sanksi perpajakan berpengaruh secara signifikan dan memiliki pengaruh positif terhadap peningkatan Pendapatan Asli Daerah di Kabupaten Jember, 2) Sikap wajib pajak tidak berpengaruh secara signifikan namun memiliki pengaruh positif terhadap peningkatan Pendapatan Asli Daerah di Kabupaten Jember, 3) Kesadaran wajib pajak tidak berpengaruh secara signifikan namun memiliki pengaruh positif terhadap peningkatan Pendapatan Asli Daerah di Kabupaten Jember, 4) Pengetahuan perpajakan tidak berpengaruh secara signifikan namun memiliki pengaruh positif terhadap peningkatan Pendapatan Asli Daerah di Kabupaten Jember, 5) Pajak Bumi dan Bangunan Perdesaan dan Perkotaan mengalami pertumbuhan atau trend positif yang cenderung mengalami peningkatan setiap tahunnya, 6) Dalam perhitungan analisis trend dengan metode least square dari tahun 2015 - 2020 menunjukkan bahwa PBB P2 sesuai dengan garis trend

\section{DAFTAR PUSTAKA}

Arikunto, S. (2010). Prosedur Penelitian: Suatu Pendekatan Praktik. Edisi Revisi. Jakarta: Penerbit Rineka Cipta.

Halim, A., Icuk R., Bawono., \& Amin, D. (2017). Perpajakan. Jakarta Selatan: PT Salemba Empat.

Harmawati, N. K. A., \& Yadnyana, I. K. (2016). Pengaruh pemahaman perpajakan, kualitas pelayanan, ketegasan sanksi pajak dan pemeriksaan pajak pada kepatuhan wajib pajak PBB-P2 dengan tingkat pendidikan sebagai pemoderasi (Studi empiris pada dinas pendapatan Kabupaten Jembrana). E-Jurnal Ekonomi dan Bisnis Universitas Udayana.

Mardiasmo. (2005). Akuntansi Sektor Publik Edisi 2. Yogyakarta: Penerbit Andi.

Sugiyono. (2008). Metode Penelitian Kuantitatif, Kualitatif dan R\&D. Bandung: Penerbit Alfabeta..

Sugiyono. (2012). Statistika untuk Penelitian. Bandung: Penerbit Alfabeta.

Suhadak \& Nugroho, T. (2007). Paradigma Baru Pengelolaan Keuangan Daerah dalam Penyusunan APBD di Era Otonomi. Malang: Bayumedia

Sutrisno. (2009). Manajemen Keuangan Teori, Konsep dan Aplikasi. Yogyakarta: Ekonisia. 